\title{
Executive Attention and Metacognitive Regulation
}

\author{
Diego Fernandez-Duque,* Jodie A. Baird, $\dagger$ and Michael I. Posner $\ddagger^{1}$
}

*Rotman Research Institute, Baycrest Centre for Geriatric Care, 3560 Bathurst Street, Toronto, Ontario, Canada M6A 1E6: †Institute of Child Study, University of Toronto, 45 Walmer Road,

Toronto, Ontario, Canada M5R 2X2; and $¥$ Sackler Institute, Department of Psychiatry, Weill Medical College of Cornell University, Box 140, 1300 York Avenue, New York, New York 10021. E-mail: diego@ rotman-baycrest.on.ca,jbaird@oise.utoronto.ca,mip2003@mail.med.cornell.edu

Metacognition refers to any knowledge or cognitive process that monitors or controls cognition. We highlight similarities between metacognitive and executive control functions, and ask how these processes might be implemented in the human brain. A review of brain imaging studies reveals a circuitry of attentional networks involved in these control processes, with its source located in midfrontal areas. These areas are active during conflict resolution, error correction, and emotional regulation. A developmental approach to the organization of the anatomy involved in executive control provides an added perspective on how these mechanisms are influenced by maturation and learning, and how they relate to metacognitive activity. ๑ 2000 Academic Press

\begin{abstract}
Metacognitively sophisticated children or adults are like busy executives, analyzing new problems, judging how far they are from the goal, allocating attention, selecting a strategy, attempting a solution, monitoring the success or failure of current performance, and deciding whether to change to a different strategy.
\end{abstract}

—J. H. Flavell, P. H. Miller, and S. A. Miller, Cognitive Development

\section{INTRODUCTION}

Metacognition is a broad term, encompassing both knowledge and regulation of cognitive activity (Moses \& Baird, 1999). Metacognitive knowledge is knowledge people have about their cognitive abilities ("I have a bad memory"), about cognitive strategies ("to remember a phone number I should rehearse it"), about tasks ("categorized items are easier to recall"), and so forth (Flavell, 1979). Metacognitive regulation refers to processes that coordinate cognition. These include both bottom-up processes called cognitive monitoring (e.g., error detection, source monitoring in memory retrieval) and top-down processes called cognitive control (e.g., conflict resolution, error correction, inhibitory control, planning, resource allocation) (Nelson \& Narens, 1990; Reder \& Schunn, 1996).

Metacognition is closely related to executive function, which involves the ability to monitor and control the information processing necessary to produce voluntary action. Despite their conceptual similarity, most of the research on metacognition and executive function has proceeded by relatively separate, independent channels (but see Carlson, Moses, \& Hix, 1998; Garner, 1994; Hughes, 1998; Mazzoni \&

This article is part of a special issue of this journal on Metacognition and Consciousness, with Thomas O. Nelson and Georges Rey as Guest Editors.

${ }^{1}$ To whom reprint requests should be addressed. 
Nelson, 1998; Metcalfe \& Shimamura, 1994). For example, metacognition researchers have been interested mostly in metacognitive knowledge, particularly in the area of metamemory. Much of this research has focused on metacognitive development and its importance for childhood education. Consequently, this approach has favored the study of metacognition in naturalistic tasks.

In contrast, the study of executive attention has been pursued by cognitive neuroscientists interested in normal adults and brain-injured patients. Cognitive neuroscience has provided an analytic approach to task performance (brought from cognitive psychology), and has tried to link cognitive control processes to brain structures (as in the tradition of cognitive neuropsychology). The emergence of brain imaging techniques has permitted the exploration of neural circuits underlying executive attention in the normal brain and, more recently, in the developing brain. For example, imaging techniques allow researchers to observe brain changes that occur as children acquire complex cognitive skills such as reading (Posner \& McCandliss, 1999) and number processing (Temple \& Posner, 1998). Other important developments, such as the emergence of inhibitory control, are also accessible via imaging methodology (Casey, Trainor, Giedd, et al., 1997). Thus, educational and developmental issues of relevance to metacognition can now be examined using the methods of cognitive neuroscience.

Figure 1 compares well-known theories of metacognition and executive function (Nelson \& Narens, 1994; Norman \& Shallice, 1986). According to recent theorizing in metacognition, cognitive processes are split into two interrelated levels: the metalevel and the object level (Nelson \& Narens, 1990). The metalevel contains a cognitive model of the object level, organized according to certain metacognitive principles. The metalevel is continuously updated by bottom-up information, and in return controls the object level by providing top-down input, initiating and terminating actions performed by the object level (Nelson \& Narens, 1994). Thus, metacognitive regulation is a metalevel system that modulates cognitive processes at the lower level. It adds flexibility to cognitive processes, making them less dependent on external cues.

Similarly, theories of executive function propose that the executive system modulates lower level schemas according to the subject's intentions (Norman \& Shallice, 1986; see also Fernandez-Duque \& Johnson, 1999). In the absence of an executive system, information is processed automatically by schemas (Posner, DiGirolamo, \& Fernandez-Duque, 1997). Consequently, without executive control, information processing loses flexibility and becomes increasingly bound to the external stimulus.

According to the model illustrated in Fig. 1, the executive system contains a model of the perceptual and cognitive functions existent at the object level. The object level contains schemas, the basic units of action and thought, which can be exogenously activated by environmental cues (i.e., automatic process). Schemas can also be endogenously activated by input from the executive system (i.e., voluntary process). Thus, schema selection depends on both sensory (bottom-up) and attentional (top-down) modulation (Norman \& Shallice, 1986).

In everyday life, metacognitive/executive control guides action when there is no adequate preestablished schema to achieve a particular goal, as in the case of a novel situation. Thus, metacognitive/executive processes are required for decision making, troubleshooting, strategy selection, and performance of nonroutine actions. These 

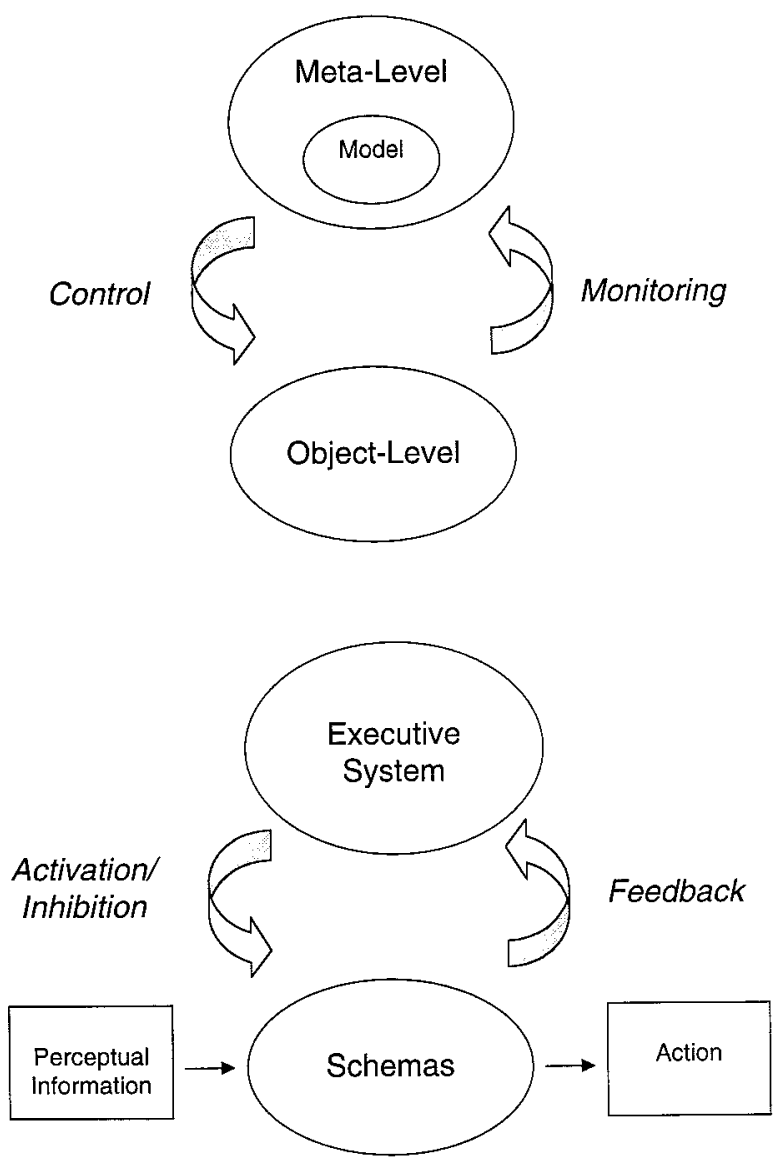

FIG. 1. The top illustrates current views on metacognition, adapted from Nelson and Narens (1994). The bottom panel illustrates models of executive attention, adapted from Norman and Shallice (1986).

cognitive tasks are crucial for human action. However, due to their complexity, it is not possible to identify their underlying physiology without first decomposing the tasks into simpler mental operations. These include conflict resolution, inhibitory control, error detection, and emotional regulation, among others. In this paper, we review the neural substrates of these basic executive functions, describe research regarding their development, and conclude by pointing to ways in which the cognitive neuroscience of executive processes can inform research on metacognition.

\section{EXECUTIVE SYSTEM}

While executive functions are likely to be instantiated by a network of brain regions, clinical studies have implicated the frontal lobes as a major contributor (Shallice, 1988; Stuss \& Benson, 1986). It is likely that different executive processes are implemented by separate, albeit interactive, frontal areas (Stuss, Shallice, Alexander, \& Picton, 1995; Umiltà \& Stablum, 1998; but see Duncan, 1995). Impairments 
of the executive system have been reported in a variety of normal and pathological states that involve the frontal lobes, including aging (West, 1996), traumatic brain injury (Strum, Willmes, Orgass, \& Hartje, 1997), frontal strokes (Duncan, 1986), dementias (Parasuraman \& Greenwood, 1998), schizophrenia (Frith, 1992), and attention deficit disorder (Barkley, 1998). Disruptions of corticostriatal loops, such as those evidenced in Parkinson's disease, also lead to deficits in executive processes (Hayes, Davidson, Keele, \& Rafal, 1998). When dysfunctions of the executive system occur, the ability to select schemas other than the one already activated becomes impaired. This sometimes leads to perseveration, that is, the recurrence of a response even in the absence of the appropriate stimulus (Milner \& Petrides, 1984). Frontal lobe lesions can also lead to increased distractibility because in the absence of topdown activation, schemas become activated by irrelevant stimuli (Shallice, 1988). Other executive deficits include poor planning (i.e., goal neglect), monitoring deficits, and memory retrieval impairments, all of which are closely related to metacognitive regulation.

Neuroimaging studies have similarly shown activation of a network of frontal areas in executive control tasks. The activated areas usually include the anterior cingulate and supplementary motor area, the orbitofrontal cortex, the dorsolateral prefrontal cortex, and portions of the basal ganglia and the thalamus. The tasks that activate these areas typically require subjects to deal with conflict, error, or emotion, therefore demanding effortful cognitive processing (Bush et al., 1998; Bush, Luu, \& Posner, 2000). These mental abilities may be the building blocks that metacognitively sophisticated thinkers use in their achievement of complex tasks, such as problem solving, strategy selection, and decision making.

We start by reviewing the neuroimaging literature, with an emphasis on conflict resolution, error detection, and emotional control. Other cognitive functions, such as planning and memory regulation, are equally important for metacognition, but the neuroimaging data currently available have not yet provided a definitive picture (see Future Research).

Conflict resolution. A classic example of attentional conflict is the well-known Stroop task (Stroop, 1935). In this paradigm, subjects are asked to name the color of ink in which a word is presented. The word itself can be a color name that is either different from the ink color (incongruent condition) or the same as the ink color (congruent condition). The resulting reaction times and error rates are compared against a neutral condition in which a noncolor word or a letter string is presented. Highly reliable interference is found when the ink color and word meaning disagree, and a less reliable but often observed facilitation is found when the ink color and word agree (MacLeod, 1991).

Neuroimaging studies of the Stroop effect have demonstrated activation of a midline attentional system in resolving the word and color conflict (Bench et al., 1993; Carter, Mintun, \& Cohen, 1995; Carter, Mintun, Nicholas, \& Cohen, 1997; Derbyshire, Vogt, \& Jones, 1998; George et al., 1994; Pardo, Pardo, Janer, \& Raichle, 1990). This area is illustrated in Fig. 2a.

Although the correspondence among studies is not exact, all studies find a midline cingulate activation when the word and ink color disagree (for reviews, see Bush et al., 1998; Posner \& DiGirolamo, 1998). Surprisingly, the congruent condition some- 


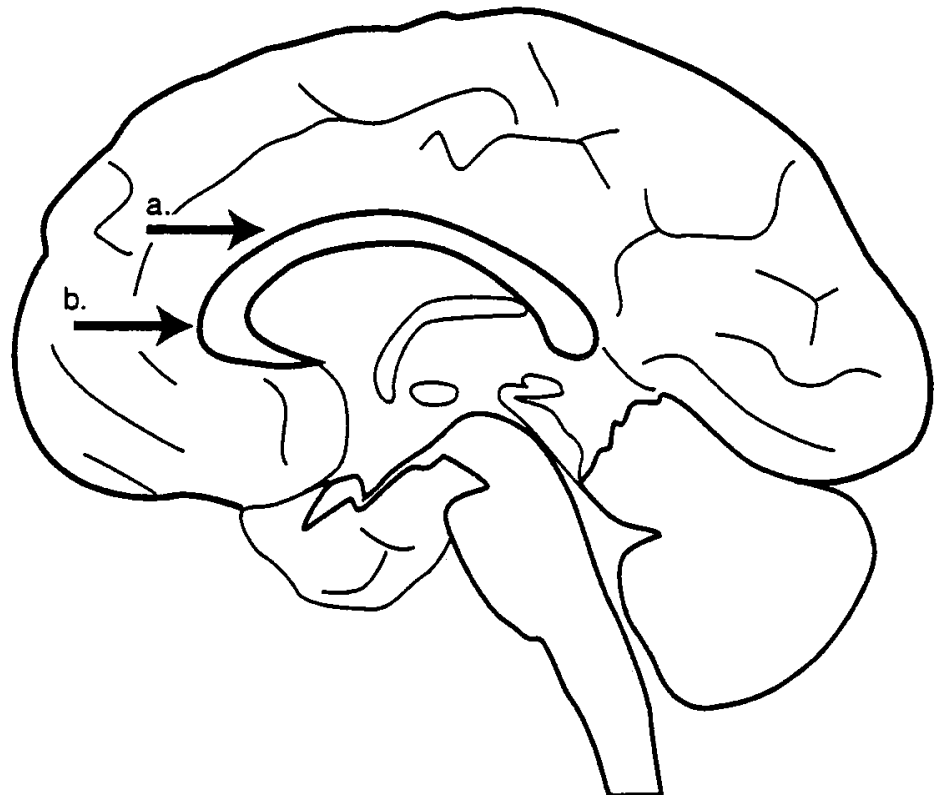

FIG. 2. Areas of the anterior cingulate activated by cognitive (Arrow a) and by emotional (Arrow b) tasks (adapted from Bush et al., 1998).

times activates the cingulate cortex relative to the neutral condition (Bench et al., 1993; Carter et al., 1995). Some researchers have postulated that comparable selective attentional processes are recruited to resolve conflict not only in the incongruent condition but also in the congruent one (Posner \& DiGirolamo, 1998; see Carter, Mintun, \& Cohen, 1995).

In support of this hypothesis, event-related potential waveforms for the incongruent and congruent condition do not diverge from each other until the subject responds, but both diverge from the neutral condition at approximately $250 \mathrm{~ms}$ (Posner \& Rothbart, 1998). Moreover, the results suggest that the activity is generated in the midfrontal areas, consistent with the results from blood flow studies. These findings suggest the activity of an executive attentional system during both congruent and incongruent conditions. Color word trials require a selection between information from the word and information from the ink color, independent of the congruity of the trial type. These data demonstrate that selecting one dimension of a multidimensional stimulus presents a situation of conflict that requires executive control mechanisms. The timing of the cingulate activation suggests that it is involved with resolving conflict between input pathways related to the ink color or to the color name in cases in which they are both active (see also Peterson et al., 1999). However, the congruent condition does not produce the subjective experience of conflict nor are there many errors in the congruent condition. Thus, in the congruent trials metacognitive knowledge (i.e., awareness) of conflict appears to be absent even though there is evidence of metacognitive regulation (i.e., selection of ink color and filtering of word meaning). This result, if confirmed, would provide convergent evidence for the existence of implicit metacognitive regulation (Reder \& Schunn, 1996). 
The anterior cingulate is also activated by other tasks that require resolution of conflict, or inhibitory control. In the "use generation" task, for example, the prepotent response (i.e., reading the word aloud) needs to be inhibited to allow the correct response to be expressed (i.e., saying the function of the word). In go/no-go tasks, the motor response needs to be inhibited whenever a no-go trial occurs. Imaging studies reveal activation of the anterior cingulate in both of these tasks (Casey, Trainor, Orendi et al., 1997; Raichle et al., 1994).

Recently, it has been proposed that the main role of the anterior cingulate is not conflict resolution, but conflict monitoring (Carter, Botvinick, \& Cohen, 1999). In this view, the anterior cingulate evaluates conditions in which conflict or errors are likely to occur, and relays this information to lateral prefrontal areas for conflict resolution. This distinction between conflict monitoring and conflict resolution maps nicely on the distinction made in the metacognitive literature between cognitive monitoring and cognitive control. Moreover, the proposed role of the anterior cingulate in evaluating situations in which errors are likely to occur is consistent with neuroimaging data revealing anterior cingulate activation after the detection of an error (see Bush, Luu, \& Posner (2000), for a discussion of this issue).

Error detection and error correction. It is common for subjects to make errors when performing a task. Normal subjects have the ability to internally evaluate their own performance, detecting errors even in the absence of any external feedback. Many studies have shown that following the detection of an error, subjects adjust the speed of their performance to achieve an adequate level of accuracy (Rabbit, 1966; Rabbit \& Rodgers, 1977; Robertson, Manly, Andrade, Baddeley, \& Yiend, 1997). This shift in the speed-accuracy trade-off is usually thought to be part of a conscious strategy. In this view, detecting an error informs subjects that their speed of response is too fast to sustain an adequate level of accuracy, and subjects react to this information by slowing down. In recent years, imaging studies have provided evidence for an error monitoring system, located in medial areas of the frontal lobe. For example, studies using evoked fMRI technique have revealed increased activation in the anterior cingulate under task conditions conducive to errors (Carter et al., 1998). Moreover, event-related potentials (ERPs) in speeded tasks reveal an errorrelated negativity on midfrontal channels. This negativity is observed after slips of action (i.e., incorrect executions of a motor program) and likely originates from the anterior cingulate (Badgaiyan \& Posner, 1998; Carter et al., 1998). For the errorrelated negativity to occur, the subject has to be aware of having made an error (Dehaene, Posner, \& Tucker, 1994; Gehring, Gross, Coles, Meyer, \& Donchin, 1993). The amplitude of the error-related negativity is larger when subjects are striving for accuracy than when speed is emphasized, consistent with the existence of a response monitoring system (Gehring et al., 1993). Finally, the error-related negativity is triggered not only by the subjects' internal feedback but also by external feedback that indicates to them that they have made an error (Badgaiyan \& Posner, 1998; Miltner, Braun, \& Coles, 1997).

Activation of the anterior cingulate is partly due to error detection, but it may also be triggered by increases in task difficulty, particularly when the difficulty reflects conflict between task elements (Carter et al., 1998). This anterior cingulate activation exists even during correct trials (i.e., trials in which error detection is absent). Since 
task difficulty is usually accompanied by a greater likelihood of errors, it is no surprise that increased difficulty is also associated with activation of the brain areas participant in error monitoring.

Monitoring and awareness of the selected response are crucial for coherent and successful behavior. Error detection informs us of our cognitive abilities and the difficulty of the task, thus contributing to the update of our metacognitive knowledge. For example, if you monitor and detect a lot of errors, you are likely to conclude that the task is difficult, or that you are not very good at it. You are more likely to ask for help or to develop compensatory strategies. A failure to detect errors might lead to faulty self-assessment and denial of deficits.

Emotional control. In most situations, feedback signals carry both cognitive and emotional information. For example, an error signal might inform subjects that they are going too fast, but it is also likely to trigger a negative emotion. There is some evidence that the valence of feedback leads to an automatic shift in response criterion even in the absence of any cognitive information (Derryberry, 1991; FernandezDuque, 1999). For example, the presentation of a valenced cue (e.g., a sad face) during a continuous performance task can slow down response and reduce future commission errors even when subjects correctly believe that the cue is uninformative about their performance (Fernandez-Duque, 1999).

Further evidence for the interaction between emotion and cognitive regulation comes from an ERP study exploring the influence of personality traits on response criterion. Relative to subjects low in negative emotionality, subjects high in negative emotionality slow down more after an error and, more importantly, show larger errorrelated negativity in the anterior cingulate (Luu, Collins, \& Tucker, 2000). This result is consistent with the view that negative emotions interact with cognitive processes at the level of the anterior cingulate.

The anterior cingulate is part of the limbic system and as such it participates in emotion processes and emotional control. There is clear evidence that anterior cingulate activation correlates with the subjective experience of pain (Craig, Reiman, Evans, \& Bushnell, 1996). For example, neuroimaging studies have revealed cingulate activity in response to heat stimuli that were judged as painful relative to stimuli that were judged merely as warm. Moreover, the cingulate appears to mediate the distress caused by pain rather than the intensity of the sensory stimulus itself (Rainville, Duncan, Price, Carrier, \& Bushness, 1997). When an effort was made to control the distress produced by a given stimulus using hypnotic suggestion, the amount of cingulate activation reflected the felt distress, while other brain areas, such as somatosensory cortex, reflected the stimulus intensity. Consistent with the role of anterior cingulate in emotional control, the anterior part of anterior cingulate is differentially activated by the expectation of a painful stimulus, while more posterior parts of the anterior cingulate are activated in response to the painful stimulus (Ploghaus et al., 1999). A possible interpretation of the anterior activation is that the subject is getting ready to control the pain associated with the incoming stimulus.

The anterior cingulate is also activated by negative emotions, such as those triggered by horrifying films and by attention to one's emotional experience (Lane, Reiman, et al., 1997). For example, one study directed subjects' attention toward the emotional dimension of a scene by requiring them to indicate the emotion it evoked (e.g., pleasant, unpleasant). Relative to a control condition in which subjects attended 
to the spatial properties of the scenes, the emotion-attended condition led to increased anterior cingulate activation (Lane, Fink, Chau, \& Dolan, 1997). Behavioral studies similarly reveal that shifting and focusing attention are important skills for emotional regulation. For example, adults who report being skillful at voluntarily shifting and focusing attention have lower negative emotionality, suggesting that effortful attention and negative affect are inversely correlated (Derryberry \& Rothbart, 1988).

The activation of midfrontal areas by tasks requiring cognitive and emotional regulation suggests that there may be a common neuroanatomy underlying these forms of executive control. However, whether this constitutes an integrated cognitive-emotional system or a set of independent modules located in the midfrontal areas is still unknown. A certain amount of structural differentiation is likely to exist, given the evidence that emotional and cognitive tasks activate somewhat separate areas of the cingulate (see Fig. 2). On the other hand, the possibility of an integrated set of subsystems in which emotion and cognition converge is consistent with the idea that emotions are an integral part of cognitive life. Thus, it is quite likely that different areas of the anterior cingulate perform distinct, albeit interacting, executive functions.

The pursuit of executive/metacognitive tasks may frequently require the inhibition or dampening of emotions, in particular ones of negative valence. Therefore, the ability to focus attention away from distressing responses most likely facilitates planning and maintenance of distant goals. It is possible that those with good inhibitory control are skilled at planning and pursuing long-term objectives, partly because they can keep those objectives in mind and suppress the irrelevant thoughts and feelings. The relevance of emotional control for metacognition is most evident in planning, where a goal needs to be maintained even in the presence of other competing options. In fact, some researchers (Kochanska, Murray, Jacques, Koenig, \& Vandegeest, 1996) have hypothesized that inhibitory control may be a good predictor of conscientiousness (i.e., constraint). In support of this, there is a close relation between the concept of inhibitory control (e.g., the ability to delay, to focus attention, and to suppress immediate desires or impulses) and the traits considered prototypical for constraint (e.g., deliberation, control of impulses, planfulness, and pursuit of distant goals) (Kochanska, 1997).

The links between emotional regulation and metacognition are also evident in the behavior of children with conduct disorders. For example, aggressive children not only have impaired executive function (Barkley, 1997; Pennington \& Ozonoff, 1996), but are also more likely to misattribute hostile intentions to others in ambiguous circumstances. This inability to assess other people's intentions reflects poor metacognitive knowledge. Furthermore, these children have impaired emotional regulation as well as great difficulty with other metacognitive tasks, such as empathy and perspective taking. The shared localization of cognitive and emotional regulation in midfrontal areas of the brain raises the possibility that these deficiencies may originate in a common neuroanatomy.

\section{DEVELOPMENT}

In the previous section we reviewed the role of midfrontal areas as they relate to the voluntary control of our thoughts and feelings. Here, we discuss recent research on how these control functions develop, as well as their possible neural correlates. 
The regulation of emotion and distress is a major aspect of infant development and one in which attention appears to play an important role. In particular, shifting and focusing attention away from a negative stimulus are effective ways to soothe an infant temporarily (Harman, Rothbart, \& Posner, 1997). In 8- and 10-month-old infants, there is a negative correlation between their ability to focus attention on a positive stimulus and the amount of expressed discomfort to an aversive stimulus (Kochanska, Coy, Tjebkes, \& Husarek, 1998).

In later infancy, the precursors of inhibitory control begin to appear. For example, in A-not-B tasks, children are trained to reach for a hidden object at location A, and then tested on their ability to search for the hidden object at a new location, B. Infants younger than 12 months of age tend to look in the previous location, A, even though they see the object disappear behind location B. After the first year, children develop the ability to inhibit the prepotent response toward the trained location, A, and successfully reach for the new location, B (Diamond \& Doar, 1989; Diamond, Werker, \& Lalonde, 1994).

During the first year of life, infants also develop some ability to resolve conflict between their line of sight and their line of reach in retrieving an object. At 9 months of age, the line of sight dominates completely, so that if the open side of a box is not in line with the side they are looking at, infants will withdraw their hand and reach along the line of sight, striking the closed side (Diamond, 1991). In contrast, 12-month-old infants are able to reach through the open end to retrieve a toy, even while looking at a closed side.

Infants can learn unambiguous associations in a sequence learning task at 4 months of age, but they do not acquire the ability to learn ambiguous associations until the age of 18 months (Clohessy, Posner, \& Rothbart, in press). In unambiguous sequences, each location is invariably associated with another location (e.g., 13241324). In this type of learning, the location of the target is fully determined by the preceding item; therefore there is no conflicting information (e.g., location " 3 "' is always followed by location ' '2'), In contrast, in ambiguous sequences (e.g., 123213123213) the response must be determined not only by the previous item but also by the context in which that item occurs (e.g., location " 3 " may be followed by location " 2 "' or by location "1") (Curran \& Keele, 1993). Ambiguous sequences pose conflict because for any association there are two strong candidates which can only be disambiguated by context.

Evidence for developmental changes in executive function and inhibitory control during the 24- to 36-month age range comes from a study using a Strooplike spatial conflict task (Caulton-Gerardi, in press). Since children of this age do not yet read, the Stroop task was modified to use location and identity as the dimensions of conflict. A simple visual object was presented on one side of a screen and children were required to press the key that matched the identity of the stimulus. The appropriate key could be either on the same side as the stimulus (congruent trial) or on the side opposite to the stimulus (incongruent trial). The prepotent response was to press the key on the side of the target irrespective of its identity. However, the task required children to inhibit that prepotent response and to act instead based on identity. The ability to resolve this conflict was measured by the accuracy and speed of their key press responses. Children 24 months of age tended to perseverate on a single response 
and performed at chance, while 36-month-old children performed at adult levels, and were slower to respond to incongruent than to congruent trials. Furthermore, conflict resolution was correlated with a battery of tasks requiring children to exercise inhibitory control over their behavior. Finally, conflict resolution was correlated with parental reports on children's effortful control and negative affect. Thus, cognitive measures of conflict resolution appear to be closely linked to aspects of children's selfcontrol in naturalistic settings.

In Stroop tasks, conflict is introduced between two elements of a single stimulus. However, only a single instruction (e.g., name the ink color) needs to be executed in any one set of trials. A more difficult conflict might be introduced by requiring subjects to utilize information from one source while, in the same set of trials, ignoring information from another. In one such task, children have to execute response commands given by a toy bear while inhibiting the commands given by a toy dragon (i.e., Bear/Dragon task). Successful performance on this type of task emerges at approximately 4 years of age (Reed, Pien, \& Rothbart, 1984).

Gerstadt, Hong, and Diamond (1994) extended a verbal conflict task modeled on the Stroop paradigm to children as young as $3 \frac{1 / 2}{2}$ years. Two cards were created to suggest day and night to the children: one depicted a line drawing of the sun, and the other depicted the moon surrounded by stars. Cards for the control condition were intended to suggest neither day nor night (e.g., picture of a checkerboard, picture of a ribbon). Children in the conflict condition were instructed to reply "day" to the moon card and "night" to the sun card. Children in the control condition were instructed to say "day" to either the checkerboard or the ribbon card and "night" to the other. At every age, accuracy scores were significantly lower for conflict relative to control trials. Although all children performed at $80 \%$ accuracy or better for the first four trials of the session, by the last four trials, the performance of the youngest children in the conflict condition declined to chance. Older children were able to maintain abovechance performance throughout the 16-trial session. Latency scores for conflict relative to control trials decreased significantly with age, suggesting that younger children needed more time to formulate their responses when faced with conflict.

Other studies using Strooplike tasks (Jerger, Martin, \& Piozzolo, 1988) and the Wisconsin Card Sorting Test (Zelazo, Resnick, \& Pinon, 1995) provide further evidence for the development of inhibitory and executive functions between the ages of 3 and 5. In the Wisconsin Card Sorting Test, children have to sort cards based on one dimension (e.g., shape), and then shift to a different dimension (e.g., color). Three-year-olds perseverate on the first dimension significantly more than 4- and 5year-olds. The Wisconsin Card Sorting Test requires not only the ability to shift the relevant dimension, but also the ability to detect that the relevant dimension has changed. Although it is possible that 3-year-olds' perseveration might be due to their failure to detect when the dimension has changed, this cannot account completely for their errors, as 3-year-olds perseverate even when the rule is made explicit by the experimenter. Interestingly, children who perseverate are capable of verbally reporting the rule (Zelazo, Frye, \& Rapus, 1996), a pattern similar to that exhibited by frontal lobe patients, who know the rule but are unable to apply it. In these cases, there is a dissociation between metacognitive knowledge and metacognitive regulation, such that knowing the rule does not guarantee its application. 
Individual differences in inhibitory control are strongly related to some aspects of metacognitive knowledge, such as theory of mind (i.e., knowing that people's behavior is guided by their beliefs, desires, and other mental states) (Carlson, 1997; Hughes, 1998). Inhibitory control and theory of mind share a similar developmental time course, with advances in both arenas between the ages of 2 and 5. Moreover, tasks that require the inhibition of a prepotent response correlate with theory of mind tasks even when other factors, such as age, intelligence, and working memory, are factored out (Carlson, 1997; Hughes, 1998).

Theory of mind tasks usually have an inhibitory component. For example, in a classic version of the false belief task (Wimmer \& Perner, 1983), children are presented with a story in which an object initially placed in location A is moved to location B. However, the actor does not see the object change location, and therefore holds a false belief about its current location. Children are asked to predict where the actor will look for the object. Successful performance on this task requires children to inhibit the prepotent stimulus (i.e., the location where the object really is) in favor of a less salient response (i.e., the location where the object is believed to be). Thus, deficits in inhibitory control might obscure children's understanding of false beliefs. Alternatively, it is possible that developments in inhibitory control might boost children's conceptual understanding of mental representations.

Another component of theory of mind is the capacity to deceive, for example by pointing to a location different from the one in which an object is hidden for the purpose of creating a false belief in someone else. Deceptive pointing abilities improve between the ages of 3 and 4 , suggesting that during this period there is a conceptual change in children's understanding of deception. However, deceptive pointing also requires inhibitory control because the most salient location (i.e., where the object really is) must be inhibited to allow for the selection of another, less salient location. In fact, 3-year-olds' performance on deception tasks can be improved by reducing the inhibitory demands of the task, for example by allowing children to point with an arrow instead of with their finger (Carlson et al., 1998). This result suggests that poor performance on these metacognitive tasks might be related to deficits in executive processes such as inhibitory control. Interestingly, preschool children described as "hard to manage"' by their parents perform poorly on inhibitory control and planning tasks (i.e., executive function tasks) as well as on theory of mind tasks (i.e., metacognitive tasks) (Hughes, Dunn, \& White, 1998).

Only in recent years has it become possible to ask about the neural substrates underlying the development of higher level cognition in the human brain. Therefore, the evidence addressing these questions is still tentative. Nevertheless, there is some evidence that the development of conflict resolution skills is related to the development of the anterior cingulate. While major changes in executive control occur between the ages of 2 and 5, executive control also develops during later childhood. In children ages 5 to 16 there is a significant correlation between the volume of the right anterior cingulate and the ability to perform tasks requiring focal attentional control (Casey, Trainor, Giedd et al., 1997). In one fMRI study, 7- to 12-year-old children and adults were tested in a go/no-go task that required them to press a key to frequent nontargets, but withhold their response to infrequent targets-a measure of inhibitory control. Relative to a control condition in which subjects responded to 
all stimuli, the condition requiring inhibitory control activated prefrontal cortex in both children and adults. Moreover, the number of false alarms in this condition was significantly correlated with the extent of cingulate activity (Casey, Trainor, Orendi et al., 1997).

\section{FUTURE RESEARCH}

We pointed out at the start of the paper that few studies have deliberately tried to relate aspects of executive function to metacognition. We hope that our paper will be useful in stimulating more talk between these fields. Below we discuss some areas of metacognition where future research may be useful in highlighting such links. These areas include metacognitive knowledge, memory regulation, and planning.

Metacognitive knowledge. The focus of our review has been on metacognitive regulation (i.e., the processes that coordinate cognition), mainly because current advances in cognitive neuroscience are most informative about these issues. However, cognitive neuroscience can also inform aspects of metacognitive knowledge, such as the subjective assessment of one's own cognitive capacities. This metacognitive ability is impaired in populations with frontal lobe dysfunction. For example, most schizophrenic patients deny having a problem, and more importantly, this denial of deficit is correlated with perseverative errors, which are a measure of executive dysfunction (Young, Davila, \& Sher, 1993).

Denial of deficit is also evident in patients with Alzheimer's disease, for whom memory impairments are correlated with an inability to assess such a deficit (Anderson \& Tranel, 1989; McGlynn \& Kaszniak, 1991). For example, Alzheimer's disease patients tend to overestimate the number of items they will be able to recall (Schacter, McLachlan, Moscovitch, \& Tulving, 1986). Interestingly, these patients are accurate in the assessment of their partner's ability (McGlynn \& Kaszniak, 1991), suggesting that the deficit stems from a self-monitoring impairment, probably involving the frontal lobes, which are known to be affected by this disease (Stuss \& Benson, 1986). Other frontal lobe pathologies, such as traumatic brain injury and Korsakoff syndrome, are also related to unawareness of deficit (McGlynn \& Kaszniak, 1991). Importantly, lesions in the medial temporal lobe, although they produce large memory deficits, do not provoke unawareness of deficit, suggesting that the unawareness of deficit is related to a dysfunction in memory monitoring or memory control.

Young children are also very poor at assessing their memory abilities. Children ages 4 to 6 overestimate their memory spans and they underestimate the amount of preparation needed to recall something without error (Flavell, Friedrichs, \& Hoyt, 1970). Children of this age also show a deficit in "feeling of knowing," which is the ability to assess performance on a future recognition task following failure in a free recall task (Wellman, 1977).

It is unknown whether these deficits in metacognitive knowledge stem from an inability to detect errors or from some other problem in metacognitive regulation. Clearly, metacognitive regulation and metacognitive knowledge are interdependent. For example, knowing that you are not very good at a certain task would lead you to monitor your progress more carefully. On the other hand, if you monitor and detect a lot of errors, you may conclude that the task is difficult, or that you are not very 
good at it. Thus, a failure to detect errors might lead to a poor assessment of one's own abilities (McGlynn \& Kaszniak, 1991).

Another point of convergence between cognitive neuroscience and metacognitive knowledge is offered by current attempts to localize the neuronal correlates of theory of mind. Theory of mind, or folk psychology, is knowledge about the existence and functioning of the mind and mental states (Flavell, 1999). As such, theory of mind is part of our more general metacognitive knowledge.

In recent years, finding the brain site of theory of mind has become a fashionable research enterprise (Baron-Cohen, 1995; Goel, Grafman, Sadato, \& Hallet, 1995; Sabbagh \& Taylor, 2000; Stone, Baron Cohen, \& Knight, 1998; for a review see Frith \& Frith, 1999). However, some cautionary notes can be taken from the last 20 years of cognitive neuroscience (for other criticisms on the modularity of theory of mind, see Moore, 1996). Research in language, visual imagery, memory, executive function, and spatial attention strongly suggests that none of these cognitive systems can be reduced to one brain area. Instead, a more likely scenario is that the brain implements cognition via interconnected networks of specialized areas, each performing a different computation. For example, there is no single brain area responsible for spatial attention; rather a network of areas including the parietal lobe, the superior colliculus, and the thalamus is operative (Posner \& Raichle, 1996). Before theory of mind can be localized in the brain, researchers should clarify the elemental mental operations involved. As Carlson's (1997) work clearly demonstrates, successful performance on many theory of mind tasks taps "general purpose" abilities such as inhibitory control, and it is likely that advances in inhibitory control play a central role in the development of theory of mind. Unless one is willing to settle for vague answers such as "the frontal lobes," asking "where in the brain is theory of mind?" may be the wrong question.

Memory regulation. An important aspect of metacognitive regulation and executive function is the ability to retrieve memories and monitor their reality. After retrieving a certain candidate answer, subjects have to monitor whether that answer is likely to be right or wrong. In other words, subjects have to assess whether or not the retrieved information is relevant to the episode they are trying to remember (Koriat \& Goldsmith, 1998). Being able to successfully differentiate relevant from irrelevant memories is key to problem solving, planning, and other complex tasks. Furthermore, memory monitoring is critical for memory tasks in which a decision about volunteering or withholding an answer is required. This decision depends on, among other things, how certain the person is about the answer being correct. Koriat and Goldsmith (1998) clearly illustrate the practical implications of metamemory in their example of a student who, after correctly answering an exam question, decides to cross the answer out. While the student's memory is correct (he did in fact write the correct answer), his memory monitoring is faulty (he believed his answer to be wrong). Memory monitoring also affects judgments of learning ("do I know this material?") and consequently allocation of study time.

In its most extreme version, failure to monitor the reality of the retrieved information gives rise to confabulations, false recognition, and source amnesia, three closely related deficits most frequently found in frontal lobe patients. Confabulation is observed in patients with Korsakoff syndrome (Dalla Barba, 1993; Moscovitch, 1995), while false recognition has been reported in a patient with right frontal lesion 
(Schacter, Curran, Galluccio, Milberg, \& Bates, 1996) as well as in normal elderly subjects. Source amnesia, the inability to remember contextual information about the circumstances under which a particular fact was acquired, is impaired in dorsolateral prefrontal patients (Shimamura, 1996), elderly subjects (Craik, Morris, Morris, \& Loewen, 1990), and young children (O'Neill \& Gopnik, 1991).

Source amnesia may involve an inability to remember the person who presented the information, the place in which information was learned, and so forth. Temporal order (i.e., "when did I learn this?') is an important aspect of source memory. Interestingly, children also exhibit deficits in source knowledge, reporting, for example, that they have always known what they have just learned (Taylor, Esbensen, \& Bennett, 1994). Moreover, children score poorly in other memory monitoring tasks, failing to use response monitoring to ensure that their answer to a question is logical. For example, they might say they saw four pictures, but choose a larger number when subsequently given an option (Brown, 1978).

The frontal lobes are important not only for memory monitoring but also for memory control and memory retrieval. For example, frontal patients (Shimamura, 1996), as well as young children (Neimark, Slotnick, \& Ulrich, 1971), fail to use encoding strategies that improve memory, such as semantic clustering, when presented with many words of the same category (Neimark et al., 1971). In normal subjects, the effort of trying to recall a memory is associated with bilateral prefrontal cortex activity, and such activation is reduced in older people, who are known to have difficulty in memory retrieval (for a review, see Norman \& Schacter, 1996).

Planning. Planning requires reflecting on which course of action is necessary to achieve a goal, and as such planning is part of metacognition (Brown, Bransford, Ferrara, \& Campione, 1983). Action planning requires establishing both a main goal (e.g., preparing dinner) and a hierarchy of subgoals that must be satisfied for the main goal to be obtained (e.g., buying groceries, following a recipe). The main goal usually guides the subgoals. However, this link appears to be impaired in frontal patients so that they might know what is required to achieve the main goal, but fail to attempt the necessary steps in behavior. A similar failure to implement task instructions is sometimes found in 3-year-old children. This disregard for task requirements has been labeled goal neglect, and appears to be related to frontal lobe function and to general intelligence (Duncan, 1995). Goal neglect reflects a dissociation between metacognitive knowledge and the application of that knowledge (i.e., metacognitive control). Thus, goal neglect is an executive dysfunction in which the top-down activation necessary for keeping a goal in mind is not provided by the executive system.

\section{CONCLUSIONS}

This is a very active period for the study of the neural basis of cognitive processes. Neuroimaging has greatly enhanced our ability to examine the brain areas involved in perception, memory, language, motor control, and many other aspects of cognition (Posner \& Raichle, 1996). The study of executive attention has been particularly important, because imaging techniques have been able to identify concrete physical structures involved in carrying out the operations of selection and other aspects of self-regulation (Posner \& Rothbart, 1998). Moreover, this work demonstrated profound links between emotional and cognitive control (Bush et al., 1998, 2000; 
Posner \& Rothbart, 1998). Executive attention is a system that undergoes a lengthy developmental process, and has profound consequences for cognitive and emotional development, volition, and consciousness, all of which are topics of great interest to students of metacognition. We hope this paper has illustrated how a productive use of concepts arising from brain-based research may enhance the study of metacognition. In turn, studies on the development of metacognitive processes should certainly help drive forthcoming research on human brain development.

\section{ACKNOWLEDGMENT}

This research was supported in part by NSF Grant BCS 9907831 to the Sackler Institute.

\section{REFERENCES}

Anderson, S. W., \& Tranel, D. (1989). Awareness of disease states following cerebral infarctation, dementia, and head trauma: Standardized assessment. The Clinical Neuropsychologist. 3, 327-339.

Badgaiyan, R., \& Posner, M. I. (1998). Mapping the cingulate cortex in response selection and monitoring. Neuroimage, 7, 255-260.

Barkley, R. A. (1998). Attention-deficit hyperactivity disorder. Scientific American, 279, 66-71.

Barkley, R. A. (1997). Behavioral inhibition, sustained attention, and executive functions: Constructing a unifying theory of ADHD. Psychological Bulletin, 12, 65-94.

Baron-Cohen, S. (1995). Mindblindness: An essay on autism and theory of mind. Cambridge, MA: MIT Press.

Bench, C. J., Frith, C. D., Grasby, P. M., Friston, K. J., Paulesu, E., Frackowiak, R. S. J., \& Dolan, R. J. (1993). Investigations of the functional anatomy of attention using the Stroop test. Neuropsychologia. 31, 907-922.

Brown, A. L. (1978). Knowing when, where, and how to remember: A problem of metacognition. In R. Glaser (Ed.), Advances in instructional psychology (pp. 77-165). Hillsdale, NJ: Erlbaum.

Brown, A. L., Bransford, J. D., Ferrara, R. A., \& Campione, J. C. (1983). Learning, remembering, and understanding. In J. H. Flavell \& E. M. Markman (Eds.), Handbook of child psychology: Vol. 3. Cognitive development (4th ed. pp. 77-166). New York: Wiley.

Bush, G., Luu, P., \& Posner, M. I. (2000). Cognitive and emotional influences in the anterior cingulate gyrus. Trends in Cognitive Sciences, 4, 215-222.

Bush, G., Whalen, P. J., Rosen, B. R., Jenike, M. A., McInerney, S. C., \& Rauch, S. L. (1998). The counting Stroop: An interference task specialized for functional neuroimaging - Validation study with functional MRI. Human Brain Mapping, 6, 270-282.

Carlson, S. M. (1997). Individual differences in inhibitory control and children's theory of mind. Unpublished doctoral dissertation, University of Oregon.

Carlson, S. M., Moses, L. J., \& Hix, H. R. (1998). The role of inhibitory processes in young children's difficulties with deception and false belief. Child Development, 69, 672-691.

Carter, C. S., Botvinick, M. M., \& Cohen, J. D. (1999). The contribution of the anterior cingulate to executive processes in cognition. Reviews in Neuroscience 10, 49-57.

Carter, C. S., Braver, T. S., Barch, D. M., Botvinick, M. M., Noll, D., \& Cohen, J. D. (1998). Anterior cingulate cortex, error detection, and the on-line monitoring of performance. Science, 280, 747749.

Carter, C. S., Mintun, M., \& Cohen, J. D. (1995). Interference and facilitation effects during selective attention: $\mathrm{An}_{2}{ }^{15} \mathrm{O}$ PET study of Stroop task performance. Neuroimage, 2, 264-272.

Carter, C. S., Mintun, M., Nicholas, T., \& Cohen, J. D. (1997). Anterior cingulate gyrus dysfunction and selective attention in schizophrenia: $\mathrm{An}\left[{ }^{15} \mathrm{O}\right] \mathrm{H}_{2} \mathrm{O}$ PET study during single-trial Stroop task performance. American Journal of Psychiatry, 154, 1670-1675. 
Casey, B. J., Trainor, R., Giedd, J., Vauss, Y., Vaituzis, C. K., Hamburger, S., Kozuch, P., \& Rapoport, J. L. (1997). The role of the anterior cingulate in automatic and controlled processes: A developmental neuroanatomical study. Developmental Psychobiology, 30, 61-69.

Casey, B. J., Trainor, R. J., Orendi, J. L., Schubert, A. B., Nystrom, L. E., Giedd, J. N., Castellanos, F. X., Haxby, J. V., Noll, D. C., Cohen, J. D., Forman, S. D., Dahl, R. E., \& Rapoport, J. L. (1997). A developmental function MRI study of prefrontal activation during performance of a go-no-go task. Journal of Cognitive Neuroscience, 9, 835-847.

Clohessy, A. B., Posner, M. I., \& Rothbart, M. K. (in press). Development of the functional visual field. Acta Psychologica.

Craig, A. D., Reiman, E. M., Evans, A., \& Bushnell, M. C. (1996). Functional imaging of an illusion of pain. Nature, 384, 258-260.

Craik, F. I. M., Morris, L. W., Morris, R. G., \& Loewen, E. R. (1990). Relations between source amnesia and frontal lobe functioning in older adults. Psychology and Aging, 5, 148-151.

Curran, T., \& Keele, S. W. (1993). Attentional and nonattentional forms of sequence learning. Journal of Experimental Psychology: Learning, Memory, \& Cognition, 19, 189-202.

Dalla Barba, G. (1993). Confabulation: Knowledge and recollective experience. Cognitive Neuropsychology, 10, 1-20.

Dehaene, S., Posner, M. I., \& Tucker, D. M. (1994). Localization of a neural system for error detection and compensation. Psychological Science, 5, 303-305.

Derbyshire, S. W. G., Vogt, B. A., \& Jones, A. K. P. (1998). Pain and Stroop interference tasks activate separate processing modules in anterior cingulate. Experimental Brain Research, 11, 52-60.

Derryberry, D. (1991). The immediate effects of positive and negative feedback signals. Journal of Personality and Social Psychology, 61, 267-278.

Derryberry, D., \& Rothbart, M. K. (1988). Arousal, affect, and attention as components of temperament. Journal of Personality \& Social Psychology, 55, 958-966.

Diamond, A. (1991). Neuropsychological insights into the meaning of object concept development. In S. Carey \& R. Gelman (Eds.), The epigenesis of mind: Essays on biology and cognition (pp. 67110). Hillsdale, NJ: Erlbaum.

Diamond, A., \& Doar, B. (1989). The performance of human infants on a measure of frontal cortex function, the delayed response task. Developmental Psychobiology, 22, 271-294.

Diamond, A., Werker, J., \& Lalonde, C. (1994). Toward understanding commonalities in the development of object search, detour navigation, categorization, and speech perception. In G. Dawson \& K. W. Fischer (Eds.), Human behavior and the developing brain (pp. 380-426). New York: Guilford.

Duncan, J. (1986). Disorganization of behavior after frontal lobe damage. Journal of Cognitive Neuropsychology, 3, 271-290

Duncan, J. (1995). Attention, intelligence, and the frontal lobes. In M. S. Gazzaniga (Ed.), The cognitive neurosciences. Cambridge, MA: MIT Press.

Fernandez-Duque, D. (1999). Automatic processing of object identity, location, and valence information. Unpublished doctoral dissertation, University of Oregon.

Fernandez-Duque, D., \& Johnson, M. L. (1999). Attention metaphors: How metaphors guide the cognitive psychology of attention. Cognitive Science, 23, 83-116.

Flavell, J. H. (1979). Metacognition and cognitive monitoring: A new area of cognitive development inquiry. American Psychologist, 34, 906-911.

Flavell, J. H. (1999). Children's knowledge about the mind. Annual Review of Psychology, 50, 21-45.

Flavell, J. H., Friedrichs, A. G., \& Hoyt, J. D. (1970). Developmental changes in memorization processes. Cognitive Psychology, 1, 324-340.

Flavell, J. H., Miller, P. H., \& Miller, S. A. (1993). Cognitive development (3rd ed.). Englewood Cliffs, NJ: Prentice Hall.

Frith, C. (1992). The neuropsychology of schizophrenia. Hillsdale, NJ: Erlbaum. 
Frith, C. D., \& Frith, U. (1999). Interacting minds-A biological basis. Science, 286, 1692-1695.

Garner, R. (1994). Metacognition and executive control. In R. B. Ruddell \& M. R. Ruddell (Eds.), Theoretical models and processes of reading (pp. 715-732). Newark, DE: International Reading Association.

Gehring, W. J., Gross, B., Coles, M. G. H., Meyer, D. E., \& Donchin, E. (1993). A neural system for error detection and compensation. Psychological Science, 4, 385-390.

George, M. S., Ketter, T. A., Parekh, P. I., Rosinsky, N., Ring, H., Casey, B. J., Trimble, M. R., Horwitz, B., Herscovitch, P., \& Post, R. M. (1994). Regional brain activity when selecting response despite interference: $\mathrm{An}_{2}{ }^{15} \mathrm{O}$ PET study of the Stroop and an emotional Stroop. Human Brain Mapping, 1, 194-209.

Gerardi-Caulton, G. (in press). Sensitivity to spatial conflict and development of self regulation in children 24-36 months of age. Developmental Science.

Gerstadt, C. L., Hong, Y. J., \& Diamond, A. (1994). The relationship between cognition and action: Performance of children $3 \frac{1}{2}-7$ years old on a Stroop-like day-night test. Cognition, 53, 129-153.

Goel, V., Grafman, J., Sadato, N., \& Hallet, M. (1995). Modeling other minds. Neuroreport, 6, 17411746.

Harman, C., Rothbart, M. K., \& Posner, M. I. (1997). Distress and attention interactions in early infancy. Motivation \& Emotion, 2, 27-43.

Hayes, A. E., Davidson, M. C., Keele, S. W., \& Rafal, R. D. (1998). Toward a functional analysis of the basal ganglia. Journal of Cognitive Neuroscience, 10, 178-198.

Hughes, C. (1998). Executive function in preschoolers: Links with theory of mind and verbal ability. British Journal of Developmental Psychology, 16, 233-253.

Hughes, C., Dunn, J., \& White, A. (1998). Trick or treat? Uneven understanding of mind and emotion and executive dysfunction in "hard-to-manage" preschoolers. Journal of Child Psychology \& Psychiatry \& Allied Disciplines, 39, 981-994.

Jerger, S., Martin, R. C., \& Pirozzolo, F. J. (1988). A developmental study of the auditory Stroop effect. Brain and Language, 35, 86-104.

Kochanska, G. (1997). Multiple pathways to conscience for children with different temperaments: From toddlerhood to age five. Developmental Psychology, 33, 228-240.

Kochanska, G., Coy, K. C., Tjebkes, T. L., \& Husarek, S. J. (1998). Individual differences in emotionality in infancy. Child Development, 69, 375-390.

Kochanska, G., Murray, K., Jacques, T. Y., Koenig, A. L., \& Vandegeest, K. A. (1996). Inhibitory control in young children and its role in emerging internalization. Child Development, 67, 490507.

Koriat, A., \& Goldsmith, M. (1998). The role of metacognitive processes in the regulation of memory performance. In G. Mazzoni \& T. Nelson (Eds.), Metacognition and cognitive neuropsychology: Monitoring and control processes. Mahah, NJ: Erlbaum.

Lane, R. D., Fink, G. R., Chau, P. M. L., \& Dolan, R. J. (1997). Neural activation during selective attention to subjective emotional responses. Neuroreport, 8, 3969-3972.

Lane, R. D., Reiman, E. M., Bradley, M. M., Lang, P. J., Ahern, G. L., Davidson R. J., \& Schwartz, G. E. (1997). Neuroanatomical correlates of pleasant and unpleasant emotion. Neuropsychologia, 35, 1437-1444.

Luu, P., Collins, P., \& Tucker, D. M. (2000). Mood, personality, and self-monitoring: Negative affect and emotionality in relation to frontal lobe mechanisms of error detection. Journal of Experimental Psychology: General, 129, 43-60.

MacLeod, C. M. (1991). Half a century of research on the Stroop effect: An integrative review. Psychological Bulletin, 109, 163-209.

Mazzoni, G., \& Nelson, T. (1998). Metacognition and cognitive neuropsychology: Monitoring and control processes. Mahah, NJ: Erlbaum.

McCandliss, B. D. (1996). Experience-based changes in cortical responses to written words. Unpublished doctoral dissertation, University of Oregon. 
McGlynn, S. M., \& Kaszniak, A. W. (1991). When metacognition fails: Impaired awareness of deficit in Alzheimer's disease. Journal of Cognitive Neuroscience, 3, 183-189.

Metcalfe, J., \& Shimamura, A. P. (Eds.). (1994). Metacognition: Knowing about knowing. Cambridge, MA: MIT Press.

Milner, B., \& Petrides, M. (1984). Behavioural effects of frontal-lobe lesions in man. Trends in Neuroscience, 7, 403-407.

Miltner, W. H. R., Braun, C. H., \& Coles, M. G. H. (1997). Event-related brain potentials following incorrect feedback in a time-estimation task: Evidence for a "generic" neural system for error detection. Journal of Cognitive Neuroscience, 9, 788-798.

Moore, C. (1996). Evolution and the modularity of mindreading. Cognitive Development, 10, 605-621.

Moscovitch, M. (1995). Confabulation. In D. L. Schacter (Ed.), Memory distortions: How minds, brains, and societies reconstruct the past. New York: Appleton-Century-Crofts.

Moses, L. J., \& Baird, J. A. (1999). Metacognition. In R. Wilson (Ed.), Encyclopedia of cognitive neuroscience. Cambridge, MA: MIT Press.

Neimark, E., Slotnick, N. S., \& Ulrich, T. (1971). Development of memorization strategies. Developmental Psychology, 5, 427-432.

Nelson, T. O., \& Narens, L. (1990). Metamemory: A theoretical framework and new findings. In G. Bower (Ed.), The psychology of learning and motivation (Vol. 26). New York: Academic Press.

Nelson, T. O., \& Narens, L. (1994). Why investigate metacognition. In J. Metcalfe \& A. P. Shimamura (Eds.), Metacognition: Knowing about knowing. Cambridge, MA: MIT Press.

Norman, K. A., \& Schacter, D. L. (1996). Implicit memory, explicit memory, and false recognition: A cognitive neuroscience perspective. In L. Y. Reder (Ed.), Implicit memory and metacognition Mahah, NJ: Erlbaum.

Norman, D. A., \& Shallice, T. (1986). Attention to action. Willed and automatic control of behavior. In R. J. Davidson, G. E. Schwartz, \& D. Shapiro (Eds.), Consciousness and self regulation (pp. 1-17). New York: Plenum.

O'Neill, D. K., \& Gopnik, A. (1991). Young children's ability to identify the sources of their beliefs. Developmental Psychology, 27, 390-397.

Parasuraman, R., \& Greenwood, P. M. (1998). Selective attention in aging and dementia. In R. Parasuraman (Ed.), The attentive brain (pp. 711-733). Cambridge, MA: MIT Press.

Pardo, J. V., Pardo, P. J., Janer, K. W., \& Raichle, M. E. (1990). The anterior cingulate cortex mediates processing selection in the Stroop attentional conflict paradigm. Proceedings of the National Academy of Sciences, U.S.A., 87, 256-259.

Pennington, B. F., \& Ozonoff, S. (1996). Executive functions and developmental psychopathology. Journal of Child Psychology \& Psychiatry \& Allied Disciplines, 37, 51-87.

Peterson, B. S., Skudlarski, P., Gatenby, J. C., Zhang, H., Anderson, A. W., \& Gore, J. C. (1999). An fMRI study of Stroop word-color interference: Evidence for cingulate subregions subserving multiple distributed attentional systems. Biological Psychiatry, 45, 1237-1258.

Ploghaus, A., Tracey, I., Gati, J. S., Clare, S., Menon, R. S., Matthews, P. M., \& Rawlins, J. N. P. (1999). Dissociating pain from its anticipation in the human brain. Science, 284, 1979-1981.

Posner, M. I., \& DiGirolamo, G. J. (1998). Executive attention: Conflict, target detection and cognitive control. In R. Parasuraman (Ed.), The attentive brain (pp. 401-423). Cambridge, MA: MIT Press.

Posner, M. I., DiGirolamo, G. J., \& Fernandez-Duque, D. (1997). Brain mechanisms of cognitive skills. Consciousness and Cognition, 6, 267-290.

Posner, M. I., \& McCandliss, B. D. (1999). Brain circuitry during reading. In R. Klein \& P. McMullen (Eds.) Converging methods for understanding reading and dyslexia (pp. 305-337). Cambridge MA: MIT Press.

Posner, M. I., \& Raichle, M. E. (1996). Images of mind. New York: Freeman.

Posner, M. I., \& Rothbart, M. K. (1998). Attention, self regulation and consciousness. Philosophical Transactions of the Royal Society of London B, 353, 1915-1927. 
Rabbit, P. M. A. (1966). Error correction time without external error signals. Nature, 212, 438.

Rabbit, P. M. A., \& Rodgers, B. (1977). What does a man do after he makes an error? An analysis of response programming. Quarterly Journal of Experimental Psychology, 29, 727-743.

Raichle, M. E., Fiez, J. A., Videen, T. O., MacLeod, A.-M. K., Pardo, J. V., Fox, P. T., \& Petersen, S. E. (1994). Practice-related changes in human brain functional anatomy during nonmotor learning. Cerebral Cortex, 4, 8-26.

Rainville, P., Duncan, G. H., Price, D. D., Carrier, B., \& Bushness, M. C. (1997). Pain affect encoded in human anterior cingulate but not somatosensory cortex. Science, 277, 968-970.

Reder, L. Y., \& Schunn, C. D. (1996). Metacognition does not imply awareness: Strategy choice is governed by implicit learning and memory. In L. Y. Reder (Ed.), Implicit memory and metacognition. Mahah, NJ: Erlbaum.

Reed, M., Pien, D. L., \& Rothbart, M. K. (1984). Inhibitory self-control in preschool children. MerrillPalmer Quarterly, 30, 131-147.

Robertson, I. H., Manly, T., Andrade, J., Baddeley, B. T., \& Yiend, J. (1997). “'Ooops!’’: Performance correlates of everyday attentional failures in traumatic brain injured and normal subjects. Neuropsychologia, 35, 747-758.

Sabbagh, M. A., \& Taylor, M. (2000). Neural correlates of 'theory of mind' reasoning in adults: An ERP study. Psychological Science, 11, 46-50.

Schacter, D. L., Curran, T., Galluccio, L., Milberg, W., \& Bates, J. (1996). False recognition and the right frontal lobe: A case study. Neuropsychologia, 34, 793-808.

Schacter, D. L., McLachlan, D. R., Moscovitch, M., \& Tulving, E. (1986). Monitoring of recall performance by memory-disordered patients [Abstract]. Journal of Clinical and Experimental Neuropsychology, 8, 130.

Shallice, T. (1988). From neuropsychology to mental structures. Cambridge, UK: Cambridge Univ. Press.

Shimamura, A. P. (1996). The role of the prefrontal cortex in controlling and monitoring memory processes. In L. Reder (Ed.), Implicit memory and metacognition. Mahah, NJ: Erlbaum.

Stone, V. E., Baron Cohen, S., \& Knight, R. T. (1998). Frontal lobe contributions to theory of mind. Journal of Cognitive Neuroscience, 10, 640-650.

Stroop, J. R. (1935). Studies of interference in serial verbal reactions. Journal of Experimental Psychology, 18, 643-662.

Strum, W., Willmes, K., Orgass, B., \& Hartje, W. (1997). Do specific attention effects need specific training? Neurological Rehabilitation, 7, 81-103.

Stuss, D. T., \& Benson, D. F. (1986). The frontal lobes. New York: Raven.

Stuss, D. T., Shallice, T., Alexander, M. P., \& Picton, T. W. (1995). A multidisciplinary approach to anterior attention functions. In J. Grafman, K. J. Holyoak, \& F. Boller F. (Eds.), Structure and functions of the human prefrontal cortex. Ann. NY Acad. of Sci.

Taylor, M., Esbensen, B. M., \& Bennett, R. T. (1994). Children's understanding of knowledge acquisition: The tendency for children to report that they have always known what they have just learned. Child Development, 65, 1581-1604.

Temple, E., \& Posner, M. I. (1998). Brain mechanisms of quantity are similar in 5-year-olds and adults. Proceedings of the National Academy of Science of the U.S.A., 95, 7836-7841.

Umiltà, C., \& Stablum, F. (1998). Control processes explored by the study of closed-head-injury patients. In G. Mazzoni \& T. O. Nelson (Eds.), Metacognition and cognitive neuropsychology: Monitoring and control processes (pp. 37-52). Mahwah, NJ: Erlbaum.

Wellman, H. M. (1977). Tip of the tongue and feeling of knowing experiences: A developmental study of memory monitoring. Child Development, 48, 13-21.

West, R. L. (1996). An application of prefrontal cortex functioning theory to cognitive aging. Psychological Bulletin, 120, 272-292. 
Wimmer, H., \& Perner, J. (1983). Beliefs about beliefs: Representation and constraining function of wrong beliefs in young children's understanding of deception. Cognition, 13, 103-128.

Young, D. A., Davila, R., \& Sher, H. (1993). Unawareness of illness and neuropsychological performance in chronic schizophrenia. Schizophrenia Research, 10, 117-124.

Zelazo, P. D., Frye, D., \& Rapus, T. (1996). An age-related dissociation between knowing rules and using them. Cognitive Development, 11, 37-63.

Zelazo, P. D., Resnick, J. S., \& Pinon, D. E. (1995). Response control and the execution of verbal rules. Developmental Psychology, 31, 508-517.

Received March 7, 2000 